\title{
REDEVELOPMENT PASAR KEMBANG CIKINI DENGAN KONSEP OPEN ARCHITECTURE SEBAGAI RUANG KETIGA DAERAH CIKINI, MENTENG
}

\author{
Erdin Yosep ${ }^{1)}$, Timmy Setiawan ${ }^{2)}$ \\ 1) Program Studi S1 Arsitektur, Fakultas Teknik, Universitas Tarumanagara, \\ erdin.315150210@stu.untar.ac.id \\ 2) Program Studi S1 Arsitektur, Fakultas Teknik, Universitas Tarumanagara, timmy@unitricipta.com

\begin{abstract}
Abstrak
Salah satu daerah dengan pengembangan ruang terbuka hijau paling signifikan di Jakarta adalah Kecamatan Menteng, Jakarta Pusat yang merupakan kota taman pertama di Indonesia. Identitas Menteng sebagai wilayah paling hijau di Jakarta justru kurang terlihat pada Pasar Kembang Cikini sebagai penyedia tanaman hias bunga tertua di Jakarta yang berada pertemuan berbagai axis perkotaan. Proyek redevelopment Pasar Kembang Cikini menjadi sebuah upaya untuk memperkuat kembali identitas pasar tradisional agar mampu bersaing dengan pasar modern. Metode perancangan yang digunakan, yaitu berangkat dari memetakan axis kawasan perkotaan tapak terpilih, menganalisa program yang dihasilkan, dan membentuk massa bangunan berdasarkan studi morfologi bangunan pasar. Sebagai sebuah ruang ketiga, konsep pasar baru yang ditawarkan menekankan kegiatan sharing dengan adanya ruang dan aktivitas yang bersifat komunal. Gabungan dari seluruh program tersebut membuat proyek ini menjadi sebuah third place yang mempertemukan masyarkat Cikini, maupun masyarakat luar untuk datang berbelanja, berekreasi, bekolaborasi, bekerja/ belajar, maupun sekedar nongkrong. Melalui perpaduan konsep arsitektur terbuka dan ekonomi kolaboratif, proyek ini bertujuan mengembangkan sebuah pasar menjadi sebuah ruang ketiga yang kontekstual dengan pengembangan hijau Menteng dan jalur budaya Ciliwung dengan mempertahankan esensinya sebagai sebuah pasar. Proyek ini didesain untuk terasa terbuka, lapang dan komunal untuk dikunjungi sebagai tempat istirahat sejenak maupun untuk kegiatan sehari - hari.
\end{abstract}

Kata kunci: kolaboratif; komunal; morfologi; pasar kembang cikini; redevelopment

\begin{abstract}
Menteng, Central Jakarta as the first Garden City in Indoneisa, served as the most significant green district in Jakarta. Located at the most green area in Jakarta, Cikini Flower Market (the oldest flower and ornamental plant center around) is less visible as the part of various urban axes. Cikini Flower Market Redevelopment is an uprising and refurbisment of local traditional marketplace against modern wholesale market. The design methods deliver from urban axis mapping, selected program analyze, and forming a building mass from study of market morphology. As a 'the third place', the concept is sharing activity with dedicated communal space and activity. All of building program, formed this project as rendezvous space for locals and outsider for shopping, recreation, collaborate, work/study, or just hangout. Through combination of open architecture and sharing economy, this project will redevelop a marketplace to contextual third place. Therefore, Cikini Flower Market will defined as the part of Menteng Green Development, and as well Ciliwung Cultural Line by maintaining it's essence as the market. Finally, this project is designed to be open, spacious, and communal place for short break or daily needs.
\end{abstract}

Keywords: cikini flower market; collaobrative; communal; morphology; redevelopment 


\section{PENDAHULUAN}

Arsitekur sebagai bagian dari masyarakat dan budaya terus berkembang seiring perubahan jaman. Salah satu produk dari perkembangan ini menghasilkan sebuah tempat yang disebut dengan third place (ruang ketiga) yang bertujuan meredefinisi arti sebuah tempat menjadi tempat baru yang dinilai lebih bermanfaat dari sebelumnya. Kehadiran sebuah Third place dalam konteks masyarakat dan kawasan perkotaan berperan sebagai pemicu terjadinya hubungan interaksi sosial yang kian berkurang. Open Architecture hadir sebagai sebuah ruang ketiga yang dapat menjadi platform arsitektur yang dapat dikombinasikan dengan berbagai kondisi masyarakat perkotaan.

Jika ditarik mundur, salah satu penerapan open architecture adalah pasar tradisional yang sudah berfungsi sebagai titik konsentrasi aktivitas masyarakat sejak lama. Pada awalnya selain menjadi tempat kegiatan jual beli, sebuah pasar secara tidak langsung merupakan sebuah third place bagi masyarakat yaitu sebagai tempat interaksi sosial, dan tempat berkumpul masyarakat. Seiring perkembangan jaman, peran pasar dalam kawasan perkotaan mulai tergantikan oleh pusat perbelanjaan modern yang menawarkan berbagai aspek yang lebih diminati masyarakat kota.

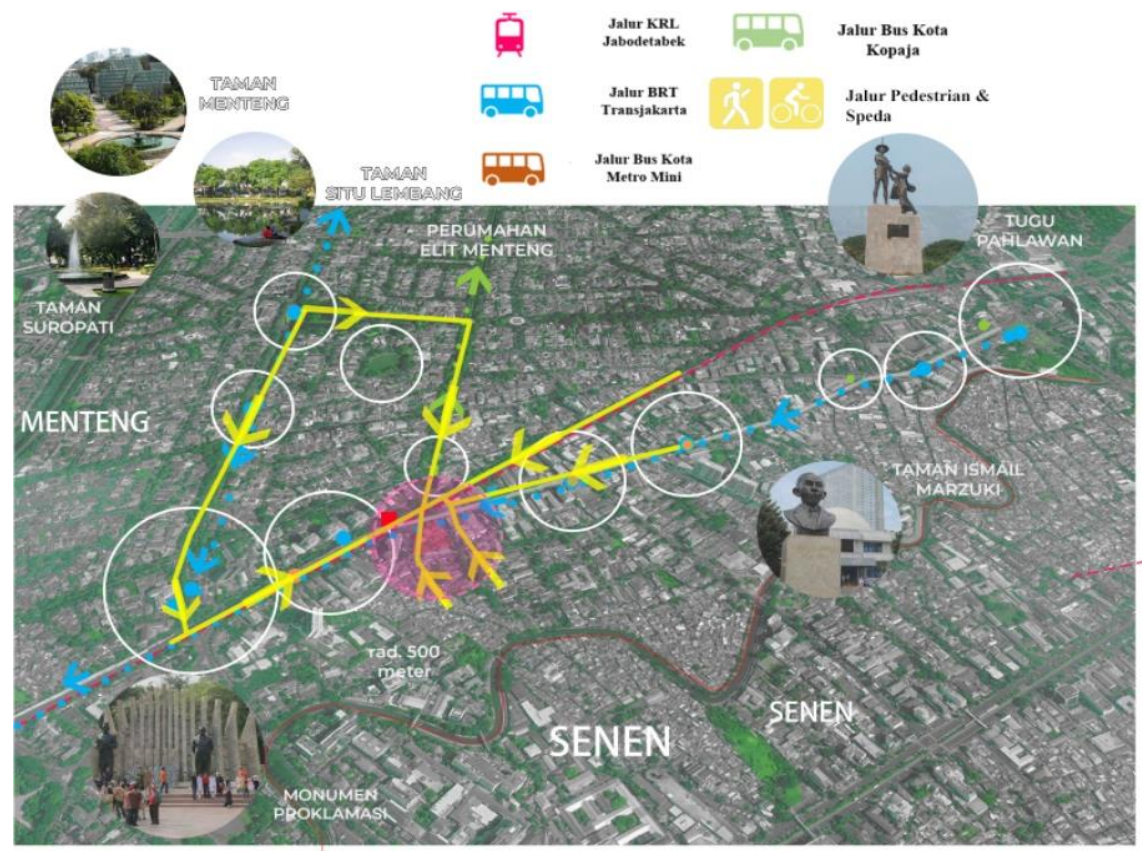

Gambar 1. Pemetaan Jalur Transportasi dan Ruang Ketiga Kawasan Sumber: Dokumentasi Pribadi

Salah satunya adalah Pasar Kembang Cikini yang terletak di kecamatan Menteng, Keluran Cikini, Jakarta Pusat. Pasar bunga hias dan parsel yang sudah berdiri sejak tahun 1962 ini pada awalnya sebagai bagian dari Pasar Hias Rias Cikini. Memasuki tahun 1990-an, maraknya pusat perbelanjaan modern mematikan pusat pertokoan lama, termasuk Pasar Hias Rias Cikini. Kini, Kawasan Pasar Kembang Cikini dipenuhi pedagang kaki lima yang pada umumnya menjual produk bunga dan parsel, ditambah dengan gedung pasar yang hanya beroperasi sebagian kecil. Proyek ini bertujuan mengembalikan dan mengembangkan fungsi pasar dengan menekankan melting pot, communal recreation space, collaborative commercial, learning and sharing economy, dan accessibility. 


\section{KAJIAN LITERATUR}

\section{Third Place dan Sharing Economy}
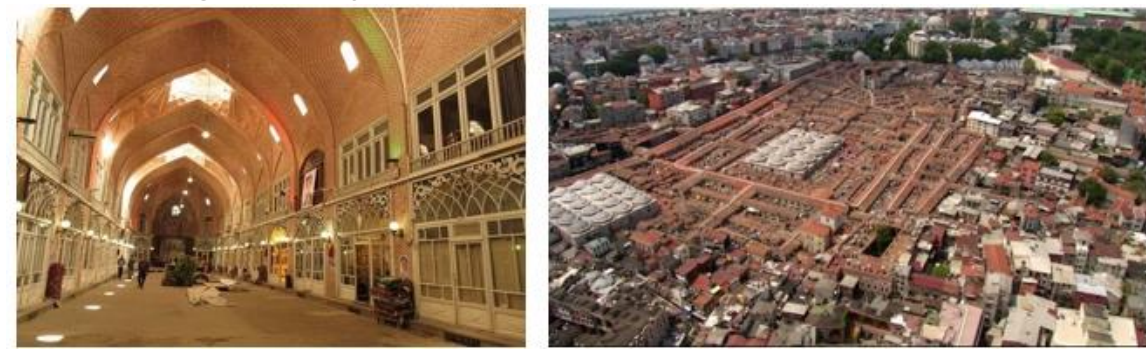

Gambar 2. Tabriz Bazaar, Iran (est.1346) dan Grand Bazaar, Turki (est.1455) Sumber: WHC UNESCO, 2010

Third place didalam konteks kota merupakan sebuah tempat yang mampu mengakomodir kebutuhan masyarakat kota yang beragam, serba cepat, rutin dan juga dinamis. Oldenberg percaya bahwa dalam suatu tatanan perkotaan terdapat suatu neutral ground yang bersifat inklusif dan sederhana bagi setiap pengunjung berdudukan sama, tanpa hirarki maupun status. Pengunjung sebuah third place bersifat regular karena sifatnya yang bersifat publik seharusnya dapat mempertemukan masyarakat sekitar mapupun masyarakat luar. Sebuah ruang ketiga juga hendaknya bersifat rekreatif bagi seluruh pengunjung yang dapat membantu menciptakan ruang bagi seluruh komunitas masyarakat. ${ }^{1}$

Sebuah third place sebagai pembentuk struktur sosial masyarakat kota dapat mendorong terbentuknya interaksi dan informasi melalui penerapan kegiatan sharing. Kegiatan berbagi sebagai produk kebudayaan yang sudah ada sejak dahulu, berfungsi menambah nilai sosial seperti halnya berbagi ruang publik, relasi dan perasaan emosional. ${ }^{2}$

\section{Pasar}

Sebuah pasar berfungsi sebagai wadah bertemunya berbagai produsen, distributor, dan konsumen dengan tujuan mencari keuntungan dan kegiatanya diatur oleh suatu regulasi. Pasar memiliki sekurang-kurangnya tiga fungsi utama, yaitu fungsi distribusi, fungsi pembentukan harga, dan fungsi promosi. For markets actually to work, products need to be created, evaluated, and priced. ${ }^{3}$ Market Device (perangkat pasar) merupakan berbagai aspek utama dan pendukung dalam menentukan regulasi yang dapat mendukung konsep pasar yang direncanakan. Perangkat pasar tersebut dapat meliputi produk dagang yang akan dijual (jenis, dan sifat produk), pelaku usaha yang berperan sebagai pengelola (stakeholders), dan calon pengunjung yang dinilai potensial sebagai pengunjung tetap.

Jika ditinjau dari teori perkotaan, sebuah tempat dapat dikategorikan sebagai sebuah jalur penghubung antar kawasan (path), simpul pusat aktivitas (nodes), penanda yang jelas untuk suatu wilayah (landmarks), mendefinisikan batas suatu / beberapa wilayah (edges), dan mendefinisikan karakteristik sebuah kawasan (districts). ${ }^{4}$

\footnotetext{
${ }^{1}$ Oldenburg, R. (1998). The Great Good Place: Cafes, Coffee Shops, Bookstores, Bars, Hair Salons, and Other Hangouts at the Heart of a Community. US: Da Capo Press

2 Mclaren,D. J,A. (2015) Sharing Cities- A Case for Truly Smart and Sustainable Cities. London : MIT Press.

${ }^{3}$ Fligstein, N. R, C. (2015) Architecture of Markets Emerging Trends in the Social and Behavioral Sciences. Univercity of California

${ }^{4}$ Lynch, K. 1960. Image of The City. Cambridge: Mass. MIT Press.
} 


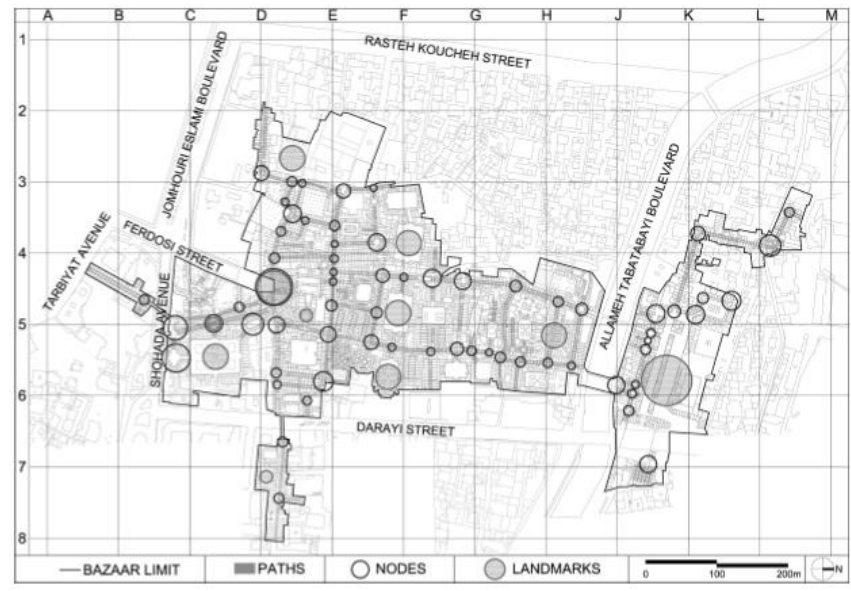

Gambar 3. Pemetaan Kawasan Pasar Tabriz Bazaar Sumber: Tabriz Municipality, 2003

"Public participation and regulation allow markets to shift from the localities of chaos and spontaneous exchange to real places of social interaction which, in their part, unite all the multinational population and the whole spectrum of social and professional distinctions" 5 Sebuah pasar bersifat inklusif, netral, dan sederhana yang dapat dilihat dari bagaimana sifatnya dapat menerima semua orang untuk berbelanja dengan harga terjangkau maupun sekedar melihat-lihat. Sebuah pasar juga pastinya memiliki pengunjung tetap yaitu penjual yang kesehariannya menawarkan barang kepada pengunjung baik dari masyarakat luar maupun masyarakat sekitarnya.

Tabel 1. Diagram Persepsi Konsumen tentang Pasar Tradisional dan Pasar Modern

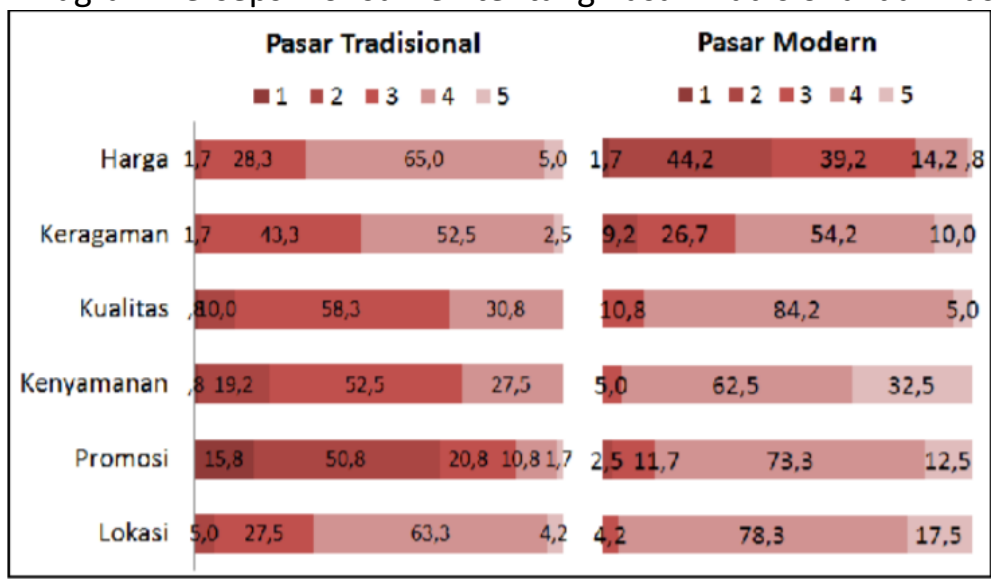

Sumber: Sadino, 2014

Fungsi pasar sebagai pusat aktivitas jual beli kini mulai tergantikan oleh pusat perbelanjaan modern dan sistem perbelanjaan online akibat kurangnya program dan aktivitas pendukung yang mampu menarik minat pengunjung terutama pada daerah perkotaan seperti Jakarta Pusat. Menurut Richard Florida terdapat tiga parameter suatu ruang publik dapat menarik datangnya masyarakat yaitu Social Offerings, Openess, dan Area Aesthethics ${ }^{6}$. Sehingga, perlu adanya sebuah konsep baru akan sebuah pasar yang dapat memenuhi ketiga kategori tersebut. Morfologi sebuah pasar (Alina Georgievskaya, 2014) dapat mempengaruhi tiga parameter ruang publik tersebut.

\footnotetext{
${ }^{5}$ Georgievskaya, A. (2015). Market - New Public Center of Local Communities. Samara State University of Architecture and Civil Engineering

${ }^{6}$ Florida, R. (2012). The Rise of the Creative Class. New York : Basic Books.
} 


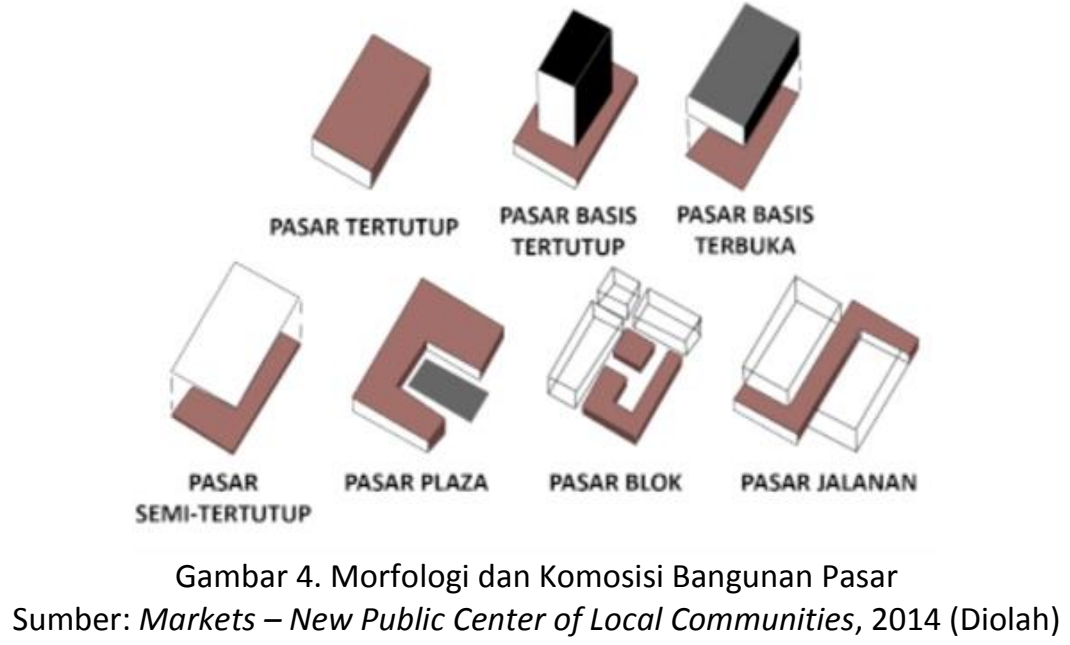

\section{Pasar Kembang}

Pasar kembang merupakan jenis pasar homogen yaitu pasar yang hanya menjual satu jenis barang yaitu produk bunga dan olahannya. Pasar kembang muncul dalam konteks mempermudah distribusi produsen bunga yang berada di daerah dataran tinggi dan konsumen di daerah perkotaan yang kesulitan mengembang biakan tanaman bunga secara alami. Pasar bunga hias merupakan salah satu jenis pasar dengan market device yang jelas dan keberadaanya diperhatikan oleh pemertintah. Hal ini dapat dilihat berdasarkan data BPS Tanaman Hias yang secara rinci mendata penjualan berbagai tanaman hias di seluruh Indonesia secara rinci. Selain itu letaknya yang berada dipusat kota dapat berpotensi menjadi ruang komunal bagi masyarakat sekitar sebagai alternatif sarana rekreasi. Terdapat sedikitnya tiga pasar kembang yang berada di Jakarta yaitu Pasar Bunga Rawa Belong (Jakarta Barat), Pasar Bunga Radio Dalam (Jakarta Selatan) dan Pasar Bunga Cikini (Jakarta Pusat).

\section{Pengertian Redevelopment}

Dari konteks perencanaan dan perancangan kota, redevelopment adalah sebuah upaya guna merumuskan peraturan pembangunan kota yang menyangkut unsur-unsur tata ruang kota yang akan diremajakan. Hasil rumusan tersebut dapat meliputi penataan kembali unsur-unsur perkotaan, seperti peruntukan lahan dan bangunan, perhitungan KDB, intensitas KDH, persentase KLB, ketinggian maximal bangunan serta unsur pendukung lainya. Di satu sisi, redevelopment bertujuan meningkatkan kemampuan ekonomis suatu lahan kawasan. Penataan kembali suatu kawasan kota terlebih dahulu melakukan pembongkaran sarana dan prasarana dari sebagian atau seluruh kawasan kota tersebut yang telah dinyatakan tidak dapat dipertahankan lagi kehadirannya. ${ }^{7}$

\section{METODE}

Menggunakan pendekatan pattern language. Pattern Language oleh Christopher Alexander yaitu hasil observasi diterjemahkan kedalam beberapa tingkatan variabel yang memprediksi strategi perancangan dari skala kawasan, skala tapak hingga skala bangunan. Prediksi tersebut menghasilkan beberapa jenis ruang aktivitas yang nantinya akan coba diterapkan kedalam desain perencanaan. ${ }^{8}$

\footnotetext{
${ }^{7}$ Danisworo, M. 1988. Konseptualisasi Gagasan dan Upaya Penanganan Proyek Peremajaan Kota: Pembangunan Kembali Sebagai Fokus. Jakarta.

${ }^{8}$ Alexander, C. S, I. M, S. (1977). A Pattern Language: Towns, Buildings, Construction. Oxford University Press.
} 


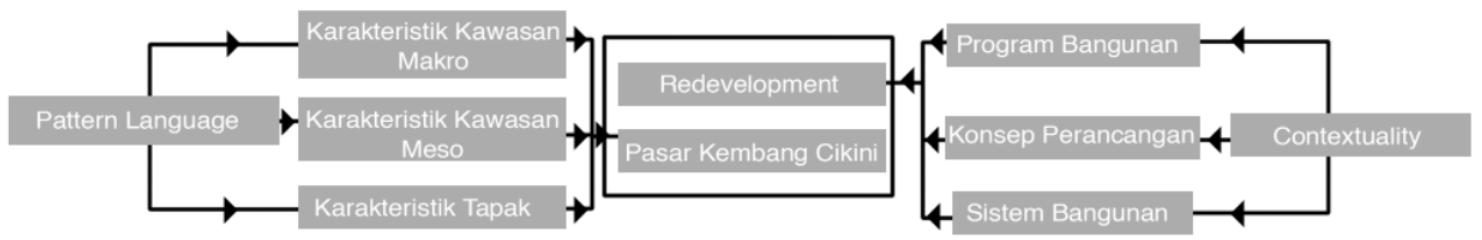

Gambar 5. Kerangka Berpikir Metode Perancangan Sumber: Dokumentasi Penulis

Nilai kontekstualitas lingkungan Menteng, Cikini juga sangat diperhatikan dalam merumuskan konsep redevelopment yang dapat menjadi aspek lokal yang istimewa. Nilai kelokakan lingkungan tersebut menciptakan sifat mixed used program dimana tiap ruang aktivitas memiliki karakteristik tersendiri yang menimbulkan penggabungan sifat ruang. Hasil dari penggabungan tersebut menjadi sebuah third place yang mencerminkan keberlangsungan pembangunan lingkungan kawasan Cikini.

\section{DISKUSI DAN HASIL}

Hasil dari tulisan ini adalah sebuah pasar yang di redevelopment menjadi pasar berfungsi campuran yaitu fungsi transit (underpass connector, halte BRT), pasar tanaman hias, galeri florikultural, co-working space, ruang multifungsi, perpusataan umum, dan area FnB seperti café dan restoran. Keberadaan beberapa program baru seperti galeri, co-working space, perpustakaan, ruang multifungsi, dan area $\mathrm{FnB}$ merupakan respon terhadap fungsi existing yaitu fungsi transit dan pasar.

Pengembangan menteng sebagai garden city pertama di Indonesia telah dimulai sejak jaman Hindia- Belanda hingga sekarang telah menjadi daerah dengan pengembangan ruang terbuka hijau paling signifikan di Provinsi DKI Jakarta. Identitas Menteng sebagai wilayah paling hijau di Jakarta justru kurang terlihat pada Pasar Kembang Cikini dapat dilihat dari lingkungan sekitarnya yang didominasi oleh ruko, gedung hotel dan perkantoran yang kurang memerhatikan intensitas kebutuhan ruang hijau. Analisa tapak yang dilakukan menggunakan metode pattern language menghasilkan sintensis yang berpotensi dapat memperkuat unsur kontekstual dalam proyek.

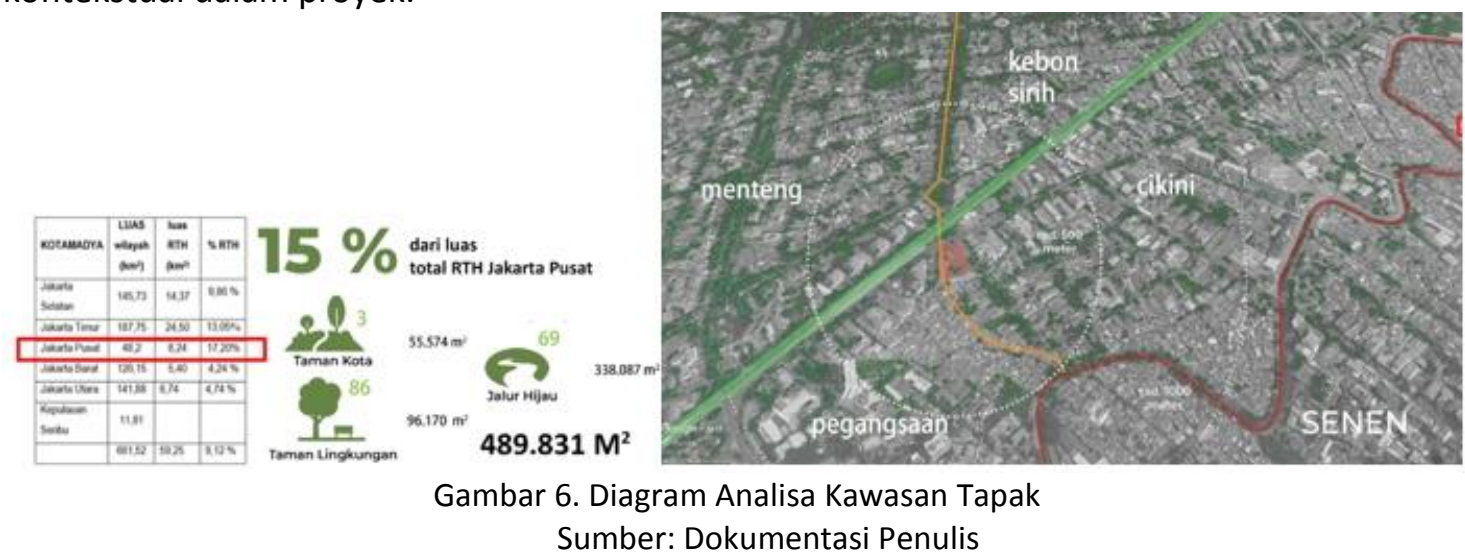

Proyek ini bertujuan untuk memperbaharui Pasar Kembang Cikini yang identik sebagai fasilitas kegiatan jual beli, menjadi sebuah ruang ketiga yang dapat menjadi sebuah ruang berkumpul bagi komunitas masyarakat Cikini dengan fasilitas penunjang bersifat kolaboratif dan rekreatif.

Konsep pasar menawarkan beragam fungsi dan aktivitas memungkinkan terbentuk berbagai aktivitas disaat yang bersamaan. Sebagai sebuah ruang ketiga, konsep pasar baru yang ditawarkan menekankan kegiatan sharing dengan adanya ruang dan aktivitas yang bersifat komunal. Sharing Economy diwujudkan melalui kolaborasi antar market device pasar kembang 
sehingga menciptakan hubungan simbiosis mutualisme antar stakeholder dan program yang ada didalamnya yaitu pihak pengelola sebagai pengatur regulasi dan kebijakan bangunan, pengerajin tanaman (florist) sebagai produsen produk olahan tanaman hias, pedagang pasar sebagai distributor tanaman hias segar sekaligus perawatan tanaman hias, dan pengunjung sebagai konsumen dapat leluasa menikmati fasilitas bangunan.

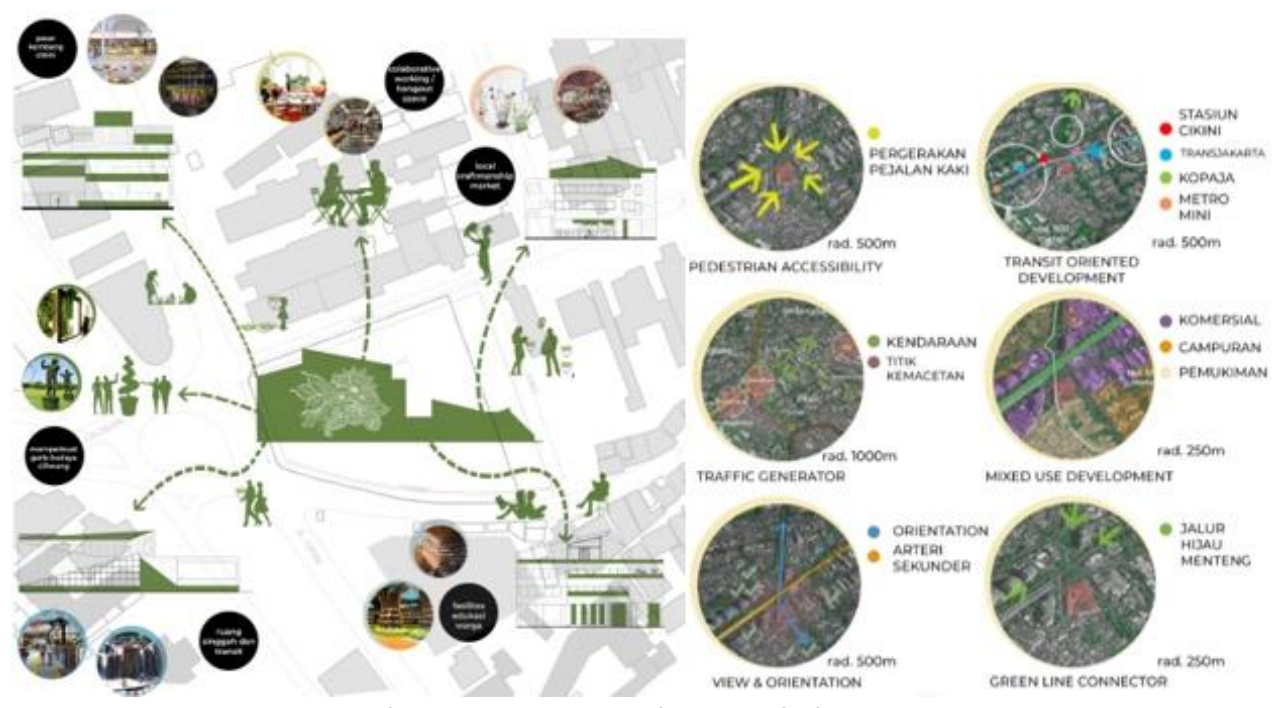

Gambar 7. Diagram Analisa Tapak dan Konsep Sumber: Dokumentasi Penulis

Proses analisa tapak dan konsep perencanaan menghasilkan suatu proses gubahan massa secara efektif dan efisien. Pergerakan kendaraan dan pedestrian menjadi poin pertama yang diperhatikan yang bertujuan menekankan konsep open architecture kedalam proyek terutama pada lantai dasar bangunan, sehingga dinding penutup ruang pada lantai dasar digunakan seminimal mungkin. Selanjutnya integrasi TOD terhadap lingkungan hal ini peletakan fungsi transit dan entrance bangunan bertujuan menghubungkan pejalan kaki dari titik transit sekitar tapak.

Pemisahan dan penggabung antar program tiap lantai memperhatikan sifat kegiatan dimana terdapat ruang bersifat public komunal dan privat komersil. Tiap ruang komersil dipisahkan alur sirkulasi berupa tangga dan dinding penutup. Sedangkan ruang publik komunal dirancang dengan akses pencapaian yang jelas dan berkesan terbuka. Alur sirkulasi dalam bangunan membentuk sirkulasi tertutup. Hal ini bertujuan mengalirkan alur pengunjung agar terus bergerak hingga anchor utama yang berada pada lantai teratas bangunan, sehingga pengunjung dapat mengunjungi tiap zona lantai.

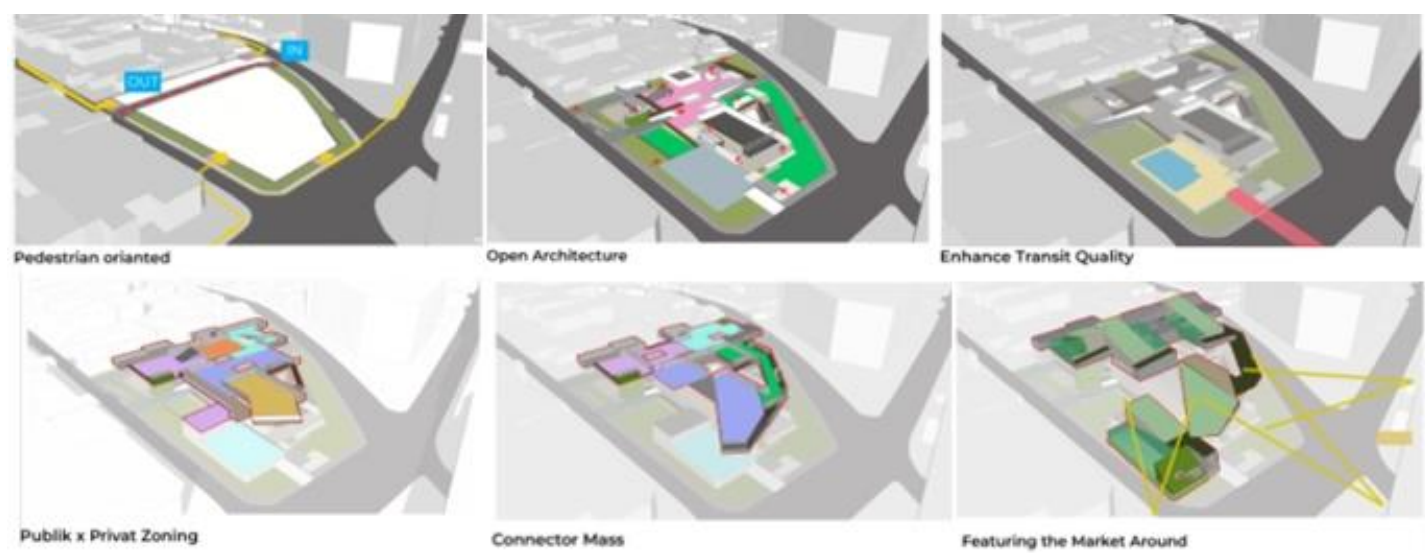

Gambar 8. Skema Perancangan Massa Bangunan Sumber: Dokumentasi Penulis 
Wujud bangunan merupakan gabungan dari dua morfolgi pasar yaitu bentuk basis tertutup dan bentuk blok. Tampilan bangunan yang kontras dengan permainan bentuk dan material dibandingkan lingkungan sekitar didukung oleh letak tapak yang ramai akan pedestrian menjadikan proyek ini juga berfungsi sebagai pedestrian trap. Penggunaan green roof yang dominan berfungsi memberi kesan hijau yang menjadi citra kawasan Menteng. Selain itu, terdapat beberapa greenroof yang dapat dimanfaatkan sebagai media display tanaman hias yang dapat dilihat secara jelas dari bangunan sekitar dengan ketinggian empat lantai atau lebih. Secara keseluruhan komposisi bangunan yang terbentuk berkesan padat namun dapat dikurangi dengan penggunaan bukaan dan unsur hijau diseluruh massa bangunan.

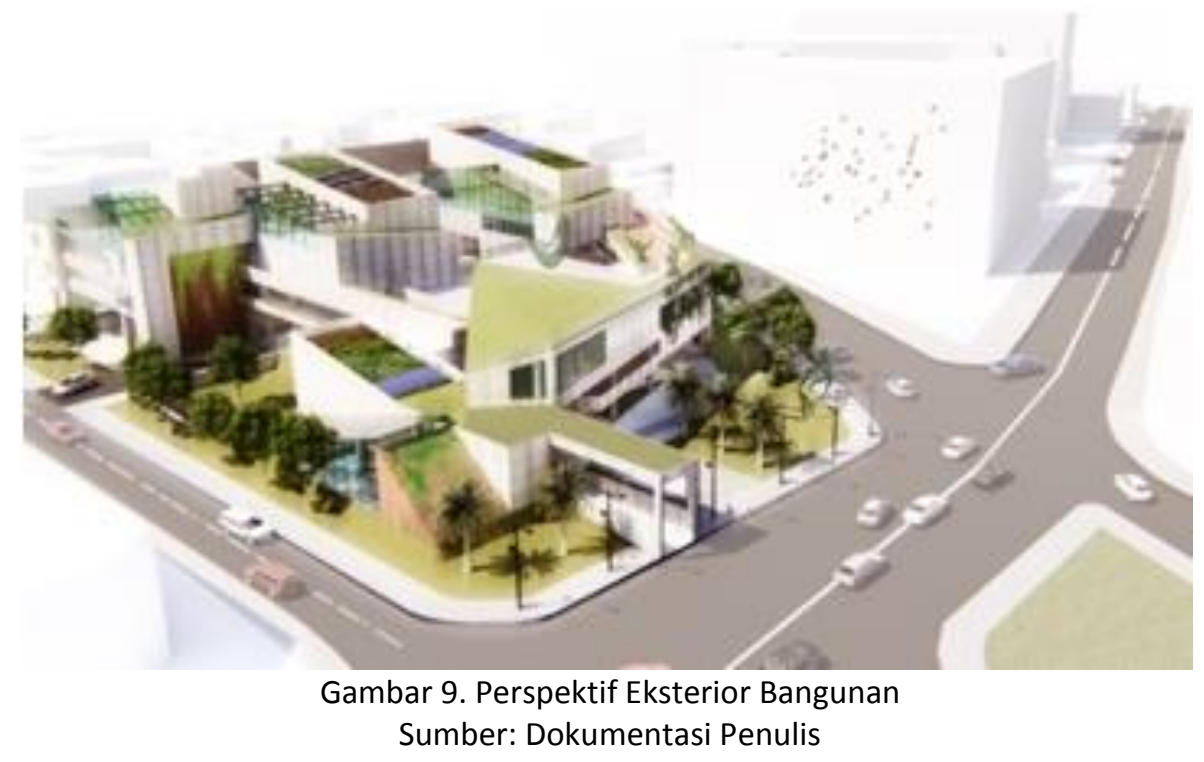

Gabungan dari seluruh program tersebut membuat proyek ini menjadi sebuah third place yang mempertemukan masyarkat Cikini, maupun masyarakat luar untuk datang berbelanja, berekreasi, bekolaborasi, bekerja / belajar, maupun sekedar nongkrong. Keterikatan antar program mengacu pada teori sharing economy dimana tiap program memiliki perannya tersendiri dengan program pasar tanaman hias sebagai program utama yang tidak dapat dipisahkan dengan program pendukung lainnya.

Fungsi pasar dan retail merupakan zona dengan persentase terbesar dimana yang dapat terlihat dari Pasar Kembang Cikini tetap dipertahankan di lantai dasar bangunan. Terdapat fungsi area $f \& b$ tersebar di lantai dasar hingga lantai 3 yang berfungsi sebagai tempat nongkrong bagi para pengunjung sehingga dapat beristirahat. Fungsi galeri berfungsi sebagai ruang pameran bagi produk olahan tanaman sekaligus berfungsi sebagai media kreativitas pengrajin bunga mapun seniman local untuk dapat berkarya. Hal ini didukung oleh tapak yang terletak dijalur budaya Ciliwung berupa banyaknya fungsi museum dan pertunjukan. Area pasar indoor berada dilantai 4 juga berfungsi sebagai tempat pembiakan dan penyimpanan tanaman hias dengan ragam jenis yang berbeda dengan area pasar dilantai dasar. Fungsi coworking space dan perpustakaan merupkan respon terhadap struktur masyarakat Menteng yang dinamis sekaligus menekankan fungsinya sebagai collaborative third place. 


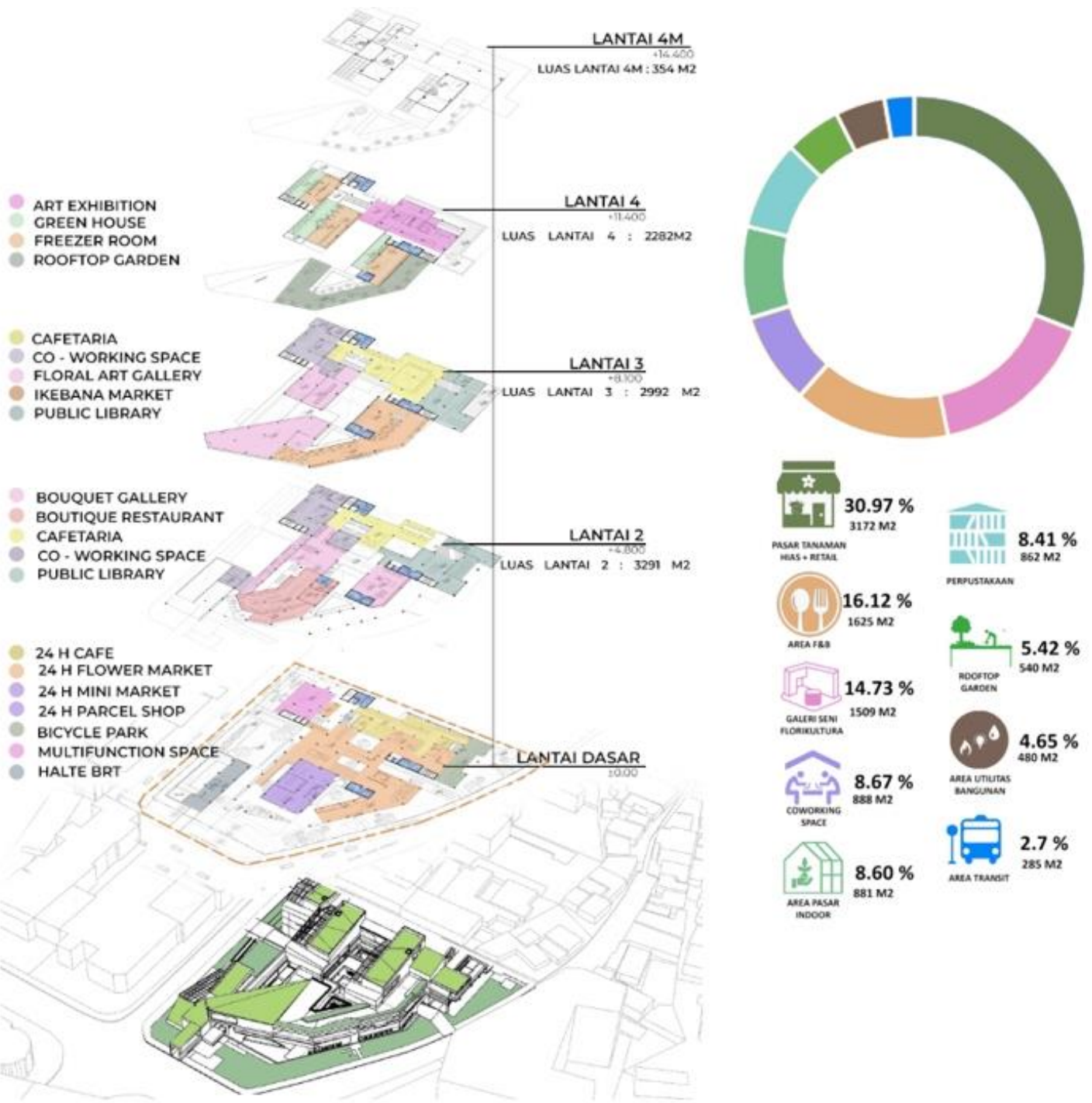

Gambar 10. Diagram Persebaran dan Persentase Program Bangunan Sumber: Dokumentasi Penulis

Material fasad bangunan pasar menggunakan material yang kontras dengan lingkungan sekitarnya. Material kayu CLT (cross laminated timber) yang dikombinasikan dengan exposed concrete screed dapat diaplikasikan sebagai dinding struktur dan material finishing, agar menghasilkan kesan natural dan ringan pada eksterior bangunan. Massa bangunan pada sisi depan memperlihatkan fungsi transit dan pasar kembang yang memanfaatkan green roof, green wall, dan planter box sebagai elemen pendukung fasad sekaligus dapat dimanfaatkan sebagai media tanam beberapa tanaman hias.

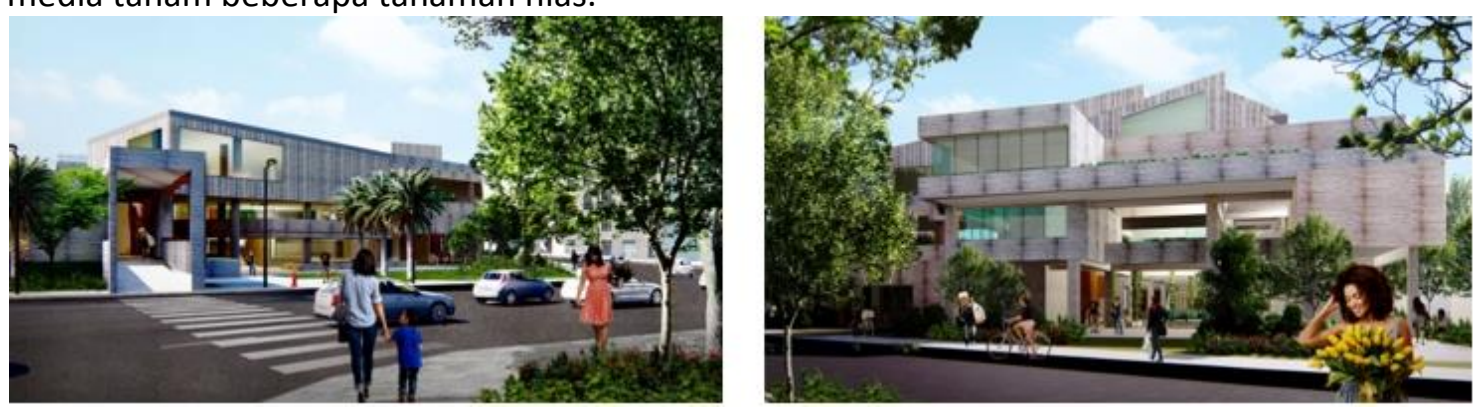

Gambar 11. Perspektif Eksterior dari Jl. Cikini Raya dan Jl. Cikini Kramat Sumber: Dokumentasi Penulis 
Membaurkan program pasar dengan area Café melalui pembatas tanpa dinding merupakan salah satu strategi agar menciptakan suasana ruang yang lebih luas akibat penerusan visual antas sisi bangunan, selain itu ruang sekitarnya akan menjadi lebih aksesibel secara psikologis. Area pasar membaur dengan jalur sirkulasi pengunjung dengan display vertikal tanaman hias agar dapat mengundang pembeli dan tidak menganggu sirkulasi pengunjung. Display tanaman hias menggunakan kaca sebagai penutup agar kualitas tanaman tetap terjaga.
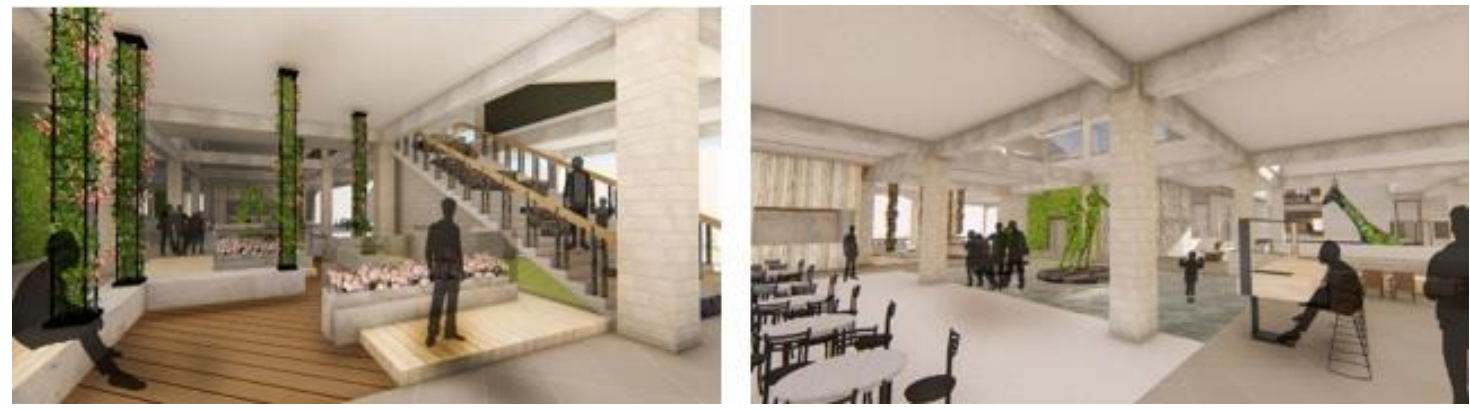

Gambar 12. Perspektif Interior Pasar Tanaman Hias dan Cafe Sumber: Dokumentasi Penulis

Area padat sirkulasi seperti koridor underpass dan selasar pasar diberi bukaan alami yang luas, hal ini bertujuan menambah penerusan visual dan aksesibilitas terhadap ruang sekitarnya. Penambahan display tanaman juga dilakukan sebagai media promosi terhadap pasar sekaligus menjadi penghias visual.
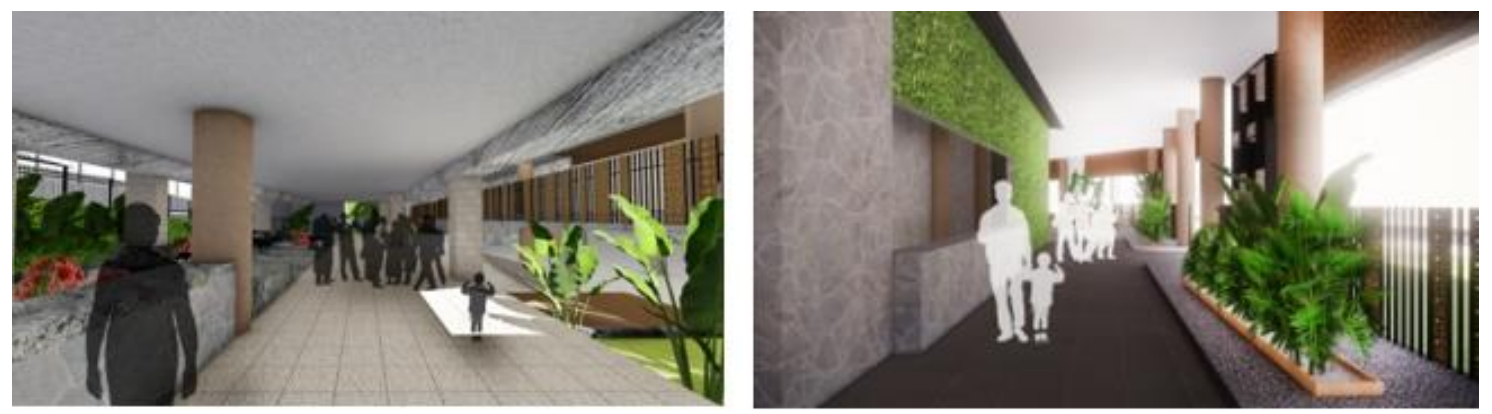

Gambar 13. Perspektif Interior Koridor Underpass dan Selasar Pasar

Sumber: Dokumentasi Penulis

Area pasar dalam ruangan berupa ruang display dan rumah kaca berfungsi sebagai tempat budidaya tanaman dengan variasi tanaman hias yang lebih banyak dibanding area pasar lantai dasar. Display gantung tanaman digunakan dengan memanfaatkan ketinggian ruangan yang juga dapat berfungsi sebagai tempat menggantung lampu maupun sprinker air.
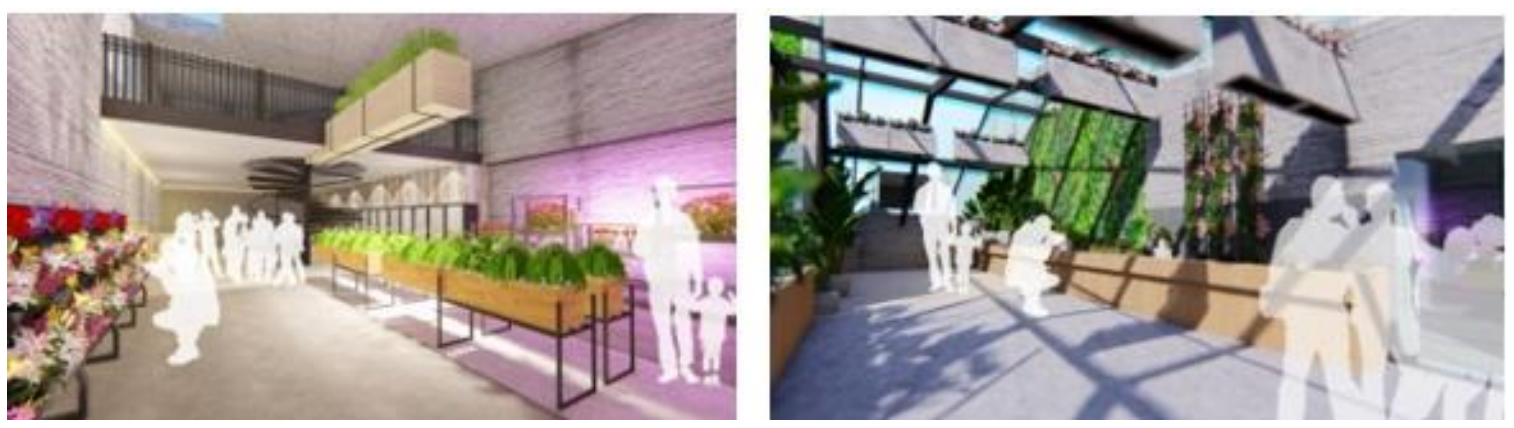

Gambar 14. Perspektif Interior Pasar Indoor dan Ruman Kaca

Sumber: Dokumentasi Penulis 


\section{KESIMPULAN DAN SARAN}

Proyek ini menekankan upaya redevelopment menjadi salah satu cara untuk meningkatkan daya saing pasar tradisional dalam menghadapi tekanan bisnis modern. Pasar Kembang Cikini sebagai sebuah ruang ketiga dapat menjadi ikon kawasan Menteng. Pasar Kembang Cikni menerapkan sistem ekonomi kolabortif dimana tiap program ruang dan user yang terlibat memiliki fungsinya masing - masing. Melalui open architecture, Pasar Kembang Cikini akan dikenal sebagai salah satu ruang komunal dan pasar yang patut diperhitungkan keberadaannya.

Hasil dari tulisan ini dapat dikembangkan kedepannya untuk mempelajari lebih lanjut bagaimana struktur ekonomi pasar dapat berfungsi melalui ilmu perancangan arsitektur sehingga dapat lebih banyak berpengaruh terhadap tata lingkungan maupun ekonomi disekitarnya dalam skala kota hingga provinsi.

\section{REFERENSI}

Alexander, C., S, I., M, S. (1977). A Pattern Language: Towns, Buildings, Construction. Oxford University Press.

Fligstein, N. R, C. (2015) Architecture of Markets Emerging Trends in the Social and Behavioral Sciences. Univercity of California.

Florida, R. (2012). The Rise of the Creative Class. New York : Basic Books.

Georgievskaya, A. (2015). Market - New Public Center of Local Communities. Samara State

Lynch, K. 1960. Image of The City. Cambridge: Mass. MIT Press.

Mclaren,D. J,A. (2015) Sharing Cities- A Case for Truly Smart and Sustainable Cities. London : MIT Press.

Oldenburg, R. (1998). The Great Good Place: Cafes, Coffee Shops, Bookstores, Bars, Hair Salons, and Other Hangouts at the Heart of a Community. US: Da Capo Press.

Shouri,A. S,D. (2009). Urban Sustainability and Market Tipologies : lessons from Tabriz Bazaar. Deakin University. 
